\title{
Relationship between socioeconomic status and HIV infection in a rural tertiary health center
}

This article was published in the following Dove Press journal:

HIVIAIDS - Research and Palliative Care

23 April 2014

Number of times this article has been viewed

Olarinde Jeffrey Ogunmola'

Yusuf Olatunji Oladosu²

Michael Adeyemi

Olamoyegun $^{3}$

'Cardiac Care Centre, Department of Internal Medicine, Federal Medical Centre, Ido-Ekiti, Ekiti State, Nigeria, ${ }^{2}$ Department of Internal Medicine, Federal Medical Centre, Ido-Ekiti, Ekiti State, Nigeria, ${ }^{3}$ Endocrinology, Diabetes and Metabolism Unit, Department of Internal Medicine, Ladoke-Akintola University of Technology Teaching Hospital, Ogbomoso, Oyo State, Nigeria

Correspondence: Olarinde Jeffrey Ogunmola

Consultant Physician and Cardiologist, Cardiac Care Center, Department of Internal Medicine, Federal Medical Center, Ido Ekiti, Ekiti State, Nigeria

Tel +23 48033880875 ;

+23480755। 6385

Email joogunmola@yahoo.com
Background: There is a scarcity of data in rural health centers in Nigeria regarding the relationship between socioeconomic status (SES) and HIV infection. We investigated this relationship using indicators of SES.

Methods: An analytical case-control study was conducted in the HIV clinic of a rural tertiary health center. Data collection included demographic variables, educational attainment, employment status, monthly income, marital status, and religion. HIV was diagnosed by conventional methods. Data were analyzed with the SPSS version 16 software.

Results: A total of 115 (48.5\%) HIV-negative subjects with a mean age of $35.49 \pm 7.63$ years (range: $15-54$ years), and $122(51.5 \%)$ HIV-positive subjects with a mean age of $36.35 \pm 8.31$ years (range: 15-53 years) were involved in the study. Participants consisted of 47 (40.9\%) men and $68(59.1 \%)$ women who were HIV negative. Those who were HIV positive consisted of $35(28.7 \%)$ men and 87 (71.3\%) women. Attainment of secondary school levels of education, and all categories of monthly income showed statistically significant relationships with HIV infection ( $P=0.018$ and $P<0.05$, respectively) after analysis using a logistic regression model. Employment status did not show any significant relationship with HIV infection.

Conclusion: Our findings suggested that some indicators of SES are differently related to HIV infection. Prevalent HIV infections are now concentrated among those with low incomes. Urgent measures to improve HIV prevention among low income earners are necessary. Further research in this area requires multiple measures in relation to partners' SES (measured by education, employment, and income) to further define this relationship.

Keywords: socioeconomic status, HIV infections, income, employment status, education, Nigeria

\section{Introduction}

Low socioeconomic status (SES) and its correlates - lower education, poverty, and poor health - characterize low- and middle-income countries such as Nigeria. According to the Central Intelligence Agency's World Factbook, Nigeria has one of the lowest gross domestic products in the world, with income of $\$ 2,800$ per capita as of July $2012 .{ }^{1}$

Domestically and internationally, human immunodeficiency virus (HIV) is a disease that is embedded in social and economic inequities, as it affects those of lower SES at a disproportionately high rate. ${ }^{2}$ Previous research suggests that a person's SES may affect his or her likelihood of contracting HIV and developing acquired immunodeficiency syndrome (AIDS).$^{3-5}$ Furthermore, SES is a key factor in determining the quality of life for individuals after they are affected by the virus. ${ }^{6}$ A lack of socioeconomic resources is linked to the practice of risky sexual behaviors, which can lead to becoming infected. ${ }^{7-9}$ 
This link has been described to have a complex relationship with religion and marital status. ${ }^{10-12}$

Nigeria has the second-largest population of people living with HIV in the world after South Africa, with only one-third of treatment-eligible individuals receiving HIV treatment. ${ }^{13}$ In 2011, the Nigerian government commissioned The President's Comprehensive Report Plan for HIV/AIDS in Nigeria ${ }^{14}$ to set target coverage levels for priority interventions. These included, for example, a 140\% increase in HIV prevention efforts among key populations. A committee of this nature requires scientific data to inform its work, and such data can provide a nexus for further investigation.

Like many low- and middle-income countries, Nigeria is predominantly rural. However, most HIV-related studies in Nigeria have targeted the urban-based population rather than the rural population that constitutes the majority of Nigerians. To the best of the authors' knowledge, studies of this nature in a rural setting such as Ekiti State are yet to be undertaken. We therefore investigated the relationship between indicators of SES and HIV prevalence in a rural tertiary hospital in Ekiti State, Nigeria. The two research questions that were tested include: 1) What are the independent effects of education, income, and employment on HIV infection? 2) How does the effect of these SES indicators change after controlling for possible confounders?

\section{Materials and methods}

This study was conducted at the HIV clinic of the Federal Medical Center of Ido Ekiti in Ekiti State. The clinic serves as a tertiary care center located in the southwest geopolitical region of Nigeria. However, large numbers of patients from Ekiti and neighboring states seek medical treatment in this hospital as a first point of contact. The HIV clinic receives patients referred as HIV-positive following a screening test with rapid assessment kits. This study was designed as an analytical case-control study to determine indicators of SES, measured as level of education attained, monthly income earned, and employment status. ${ }^{6}$ The populations studied consisted of HIV-positive patients (case group) who were compared with age- and sex-matched HIV-negative subjects (control group). The latter group was drawn from the patients' relatives, hospital staff, and volunteer members of the community. The analytical sample for this study was limited to those with conventional evaluation of HIV diagnosis using enzyme-linked immunosorbent assay and Western blot assay techniques. Exclusion criteria were subjects who had an indeterminate HIV test result, or subjects with incomplete evaluation or data relevant to this study. All participants were recruited consecutively. Age, religion, and marital status were considered as confounders.

The ethics committee of the Federal Medical Center, Ido Ekiti, Ekiti State approved the study. Individuals gave informed consent to participate in the study. All data were anonymized in the analysis. Individual participant written consent was obtained after thorough explanation was conducted and understanding about the study was established. Confidentiality was assured to all participants, and data utilized for this study were stripped of personally identifiable information.

The minimum sample size was calculated using a formula for estimating proportions with populations of less than 10,000: $n f=n / 1+n / N$. The value $n f$ is the desired sample size when the population is less than 10,000; $\mathrm{N}$ is the estimated population size (this was estimated as the average of 168 new HIV patients seen annually in the HIV clinic); $n$ is obtained using the formula $n=$ $\mathrm{z}^{2} \mathrm{pq} / \mathrm{d}^{2}$, where $\mathrm{z}$ is the normal standard deviation using a $95 \%$ confidence level of 1.96 ; $p$ is the proportion of the target population estimated to have a particular characteristic (the prevalence of HIV in Nigeria is 3.6\%); ${ }^{15} \mathrm{q}$ is obtained using the formula $1.0-\mathrm{p}$; and $\mathrm{d}$ is the degree of accuracy desired, set at 0.05 .

Thus,

$$
\mathrm{n}=(1.96)^{2} \times 0.036 \times 0.964 /(0.05)^{2}=53.328
$$

and

$$
\mathrm{nf}=53.328 / 1+53.328 / 168=40.48 \text {. }
$$

So, the minimum sample size for this study is 40 . To increase the probability that our study would be able to detect an effect, the sample size was increased to 115 and 122 subjects in the control and case groups, respectively.

Eligible participants were personally interviewed and enrolled using a structured questionnaire to collect data on the demographic characteristics and variables of interest. These included age, sex, marital status (classified as single, married, separated, divorced, widowed, or remarried), educational attainment (classified as none, primary, secondary, or tertiary), employment status (categorized as full-time, part-time, or unemployed), and monthly income in Naira (categorized as low income, <40,000 Naira; middle income, 40,000-80,000 Naira; or high income, $>80,000$ Naira). This categorization was based on the Federal Civil Service structure of Nigeria. Religious affiliation was categorized as Christian, Muslim, or other. HIV status was assessed by HIV-1/HIV-2

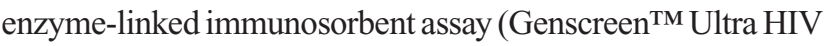
Ag-Ab; Bio-Rad Laboratories, Hercules, CA, USA) of EDTA 
anticoagulated blood samples at the National Blood Transfusion Service Laboratory (owned by the Federal Government of Nigeria to provide safe blood). Reactive samples were confirmed using Western blot I and II confirmation kits (New Lav-Blot I and II; Bio-Rad Laboratories).

All data collection was undertaken by the same set of trained research personnel and completed in the same laboratories using identical instruments and assays for the two groups.

\section{Data analysis}

The proportions of categorical variables were calculated, and tests of statistical significance performed using the chi-square test or Fisher's exact test. Means and standard deviations of the continuous variables were calculated, and the Student's $t$-test was used to assess statistical significance. A multivariate binary logistic regression model was applied to test the independent role of different confounders. In these tests, a $P$-value of $<0.05$ was considered statistically significant. The data were analyzed using the Statistical Package for the Social Sciences version 16 (SPSS Inc., Chicago, IL, USA).

\section{Results}

HIV-negative and HIV-positive subjects accounted for 115 and 122 subjects of the control and case groups studied as shown in Table 1. In addition, Table 1 shows the univariate characteristics of the study groups, both of which were age and sex matched ( $P=0.219$ and $P>0.05$, respectively). In the HIV-negative subjects, the mean age was $35.49 \pm 7.63$ years, and the range was 15-54 years. For the HIV-positive subjects the mean age was $36.35 \pm 8.31$ years, and the range was 15-53 years. The highest number of HIV-positive individuals was found in the group aged 30-39 years. In educational attainment, those without education were comparable in both groups $(P=0.388)$. However, those with tertiary education were found more frequently among the HIV-negative subjects $(P<0.001)$, in contrast to the HIV-positive subjects who were more likely to have primary or secondary school education ( $P=0.004$ and $P=0.001$, respectively). Analysis of the monthly income of participants showed that, in contrast to HIV-negative subjects, HIV-positive subjects were found predominantly in the low-income category $(P<0.05)$. There was no statistically significant difference in employment status $(P>0.05)$, marital status $(P>0.05)$, or religion $(P>0.05)$.

Binary logistic regression analysis (Table 2 ) showed that the age group of 30-39 years, secondary school educational attainment, and all categories of monthly income were independent predictors of HIV infection $(P<0.05)$. An addi-
Table I Characteristics of study participants

\begin{tabular}{|c|c|c|c|}
\hline Variable & $\begin{array}{l}\text { HIV negative } \\
(n=I 15)\end{array}$ & $\begin{array}{l}\text { HIV positive } \\
(n=122)\end{array}$ & $P$-value \\
\hline Age (years)* & $35.49 \pm 7.63$ & $36.35 \pm 8.31$ & 0.219 \\
\hline Range & $(15-54)$ & $(15-53)$ & \\
\hline \multicolumn{4}{|c|}{ Age group (years)** } \\
\hline$<30$ & II (9.6\%) & $13(10.7 \%)$ & 0.683 \\
\hline $30-39$ & $48(41.7 \%)$ & $5 \mathrm{I}(4 \mathrm{I} .8 \%)$ & 0.840 \\
\hline $40-49$ & $36(31.3 \%)$ & $41(33.6 \%)$ & 0.569 \\
\hline $50-59$ & $20(17.4 \%)$ & 17 (13.9\%) & 0.622 \\
\hline \multicolumn{4}{|l|}{ Sex** } \\
\hline Male & 47 (40.9\%) & $35(28.7 \%)$ & 0.185 \\
\hline Female & $68(59.1 \%)$ & 87 (7I.3\%) & 0.127 \\
\hline \multicolumn{4}{|l|}{ Education** } \\
\hline None & $4(3.5 \%)$ & $8(6.5 \%)$ & 0.388 \\
\hline Primary & 5 (4.4\%) & $19(15.6 \%)$ & 0.004 \\
\hline Secondary & $25(21.7 \%)$ & 54 (44.3\%) & 0.001 \\
\hline Tertiary & 81 (70.4\%) & 41 (33.6\%) & $<0.001$ \\
\hline \multicolumn{4}{|l|}{ Employment** } \\
\hline Full-time & 104 (90.5\%) & 110 (90.2\%) & 0.682 \\
\hline Part-time & $2(1.7 \%)$ & $5(4.1 \%)$ & 0.453 \\
\hline Unemployed & $9(7.8 \%)$ & $7(5.7 \%)$ & 0.617 \\
\hline \multicolumn{4}{|c|}{ Monthly income in Naira** } \\
\hline$<40,000$ & $57(49.6 \%)$ & $100(82.0 \%)$ & 0.014 \\
\hline $40,000-80,000$ & $20(17.4 \%)$ & $8(6.5 \%)$ & 0.023 \\
\hline$>80,000$ & $38(33.0 \%)$ & $14(11.5 \%)$ & 0.001 \\
\hline \multicolumn{4}{|l|}{ Marital status** } \\
\hline Single & $26(22.6 \%)$ & $16(13.1 \%)$ & 0.123 \\
\hline Married & 75 (65.2\%) & 77 (63.1\%) & 0.871 \\
\hline Separated & $2(1.7 \%)$ & $4(3.3 \%)$ & 0.414 \\
\hline Divorced & $3(2.6 \%)$ & $6(4.9 \%)$ & 0.508 \\
\hline Widowed & 7 (6.2\%) & 14 (1 I.5\%) & 0.127 \\
\hline Remarried & $2(1.7 \%)$ & $5(4.1 \%)$ & 0.453 \\
\hline \multicolumn{4}{|l|}{ Religion** } \\
\hline Christian & II 3 (98.3\%) & II 5 (94.3\%) & 0.894 \\
\hline Muslim & $2(1.7 \%)$ & $7(5.7 \%)$ & 0.096 \\
\hline
\end{tabular}

Note: *Mean \pm standard deviation; **proportion.

Abbreviation: HIV, human immunodeficiency virus.

tional finding was that the lower the education level attained and the lower the income earned per month, the higher the risk of HIV infection. Figure 1 shows the distribution of education by age group according to HIV status. In HIV-positive subjects, no education or primary school education predominated in most of the age groups, in contrast to HIV-negative subjects where tertiary education predominated. Similarly, low or intermediate income predominated in HIV-positive subjects, in contrast to HIV-negative subjects where high income predominated (Figure 2).

\section{Discussion}

To our knowledge, this study was the first exploration of the relationship between SES and HIV infection in a rural tertiary hospital in Ekiti State, Nigeria. Although it has been 27 years since HIV was first reported in Nigeria in 1986, hospital 
Table 2 Multivariate binary regression model relating HIV infection to socioeconomic variables and confounders

\begin{tabular}{|c|c|c|c|c|c|c|c|c|}
\hline \multirow[t]{2}{*}{ Variables } & \multirow[t]{2}{*}{ B } & \multirow[t]{2}{*}{ SE } & \multirow[t]{2}{*}{ Wald } & \multirow[t]{2}{*}{$d f$} & \multirow[t]{2}{*}{$P$-value } & \multirow[t]{2}{*}{ OR (EXP[B]) } & \multicolumn{2}{|c|}{$95 \% \mathrm{Cl}$ for $\mathrm{OR}$} \\
\hline & & & & & & & Lower & Upper \\
\hline \multicolumn{9}{|l|}{ Age group (years) } \\
\hline $20-29$ & & & 4.833 & 3 & 0.184 & & & \\
\hline $30-39$ & 1.664 & 0.817 & 4.147 & I & 0.042 & 5.282 & 1.064 & 26.213 \\
\hline $40-49$ & 0.734 & 0.720 & 1.039 & I & 0.308 & 2.083 & 0.508 & 8.544 \\
\hline $50-59$ & 0.813 & 0.706 & 1.324 & I & 0.250 & 2.254 & $0.56 \mathrm{I}$ & 9.001 \\
\hline Sex [Female (male as reference)] & 0.091 & 0.370 & 0.061 & I & 0.806 & 1.095 & 0.531 & 2.261 \\
\hline \multicolumn{9}{|l|}{ Education } \\
\hline None & & & 7.487 & 3 & 0.058 & & & \\
\hline Primary & -0.177 & 1.160 & 0.023 & I & 0.879 & 1.194 & 0.123 & 11.596 \\
\hline Secondary & -2.634 & 1.110 & 5.625 & 1 & 0.018 & 0.072 & 0.008 & 0.633 \\
\hline Tertiary & -0.699 & 0.414 & 2.855 & I & 0.091 & 0.497 & 0.221 & 1.118 \\
\hline Employment status & -0.120 & 1.158 & 0.011 & I & 0.917 & 0.887 & 0.092 & 8.580 \\
\hline \multicolumn{9}{|l|}{ Income (naira) } \\
\hline below 40,000 & & & 9.145 & 2 & 0.010 & & & \\
\hline $40,000-80,000$ & -1.596 & 0.543 & 8.630 & I & 0.003 & 0.203 & 0.070 & 0.588 \\
\hline above 80,000 & -1.463 & 0.597 & 6.008 & I & 0.014 & 0.231 & 0.072 & 0.746 \\
\hline Marital status & -0.465 & 0.213 & 2.856 & 1 & 0.091 & 0.498 & 0.413 & 0.954 \\
\hline Religion & -1.111 & 1.459 & 0.581 & I & 0.446 & 0.329 & 0.019 & 5.740 \\
\hline Constant & 2.965 & 2.100 & 1.994 & I & 0.158 & 19.397 & & \\
\hline
\end{tabular}

Notes: Age group ( $<30$ years), sex (male), educational attainment (no education), and income code ( $<40,000$ [Naira]) serve as baseline references; constant, baseline odds estimated for HIV infection when independent variables are absent

Abbreviations: $\mathrm{Cl}$, confidence interval; $\mathrm{df}$, degrees of freedom; HIV, human immunodeficiency virus; OR, odds ratio; $\mathrm{SE}$, standard error; Wald, Wald statistic based on the sample estimate; $\operatorname{EXP(B),~estimated~odds~ratio.~}$

studies on HIV in Nigeria have most often been conducted in urban tertiary health centers.

Our study was consistent with the current knowledge indicating that the preponderance of HIV-positive individuals are female. ${ }^{15}$ However, the peak age group in this study was 30-39 years, unlike the documented peak age group of
25-29 years in Nigeria. ${ }^{15}$ The age group found in this study may be related to the late hospital presentation that is common in our environment. ${ }^{16}$ Nonetheless, a study undertaken in Tanzania reported a similar peak age group. ${ }^{17}$

Understanding the relationship between SES and HIV risk can have important implications for designing and

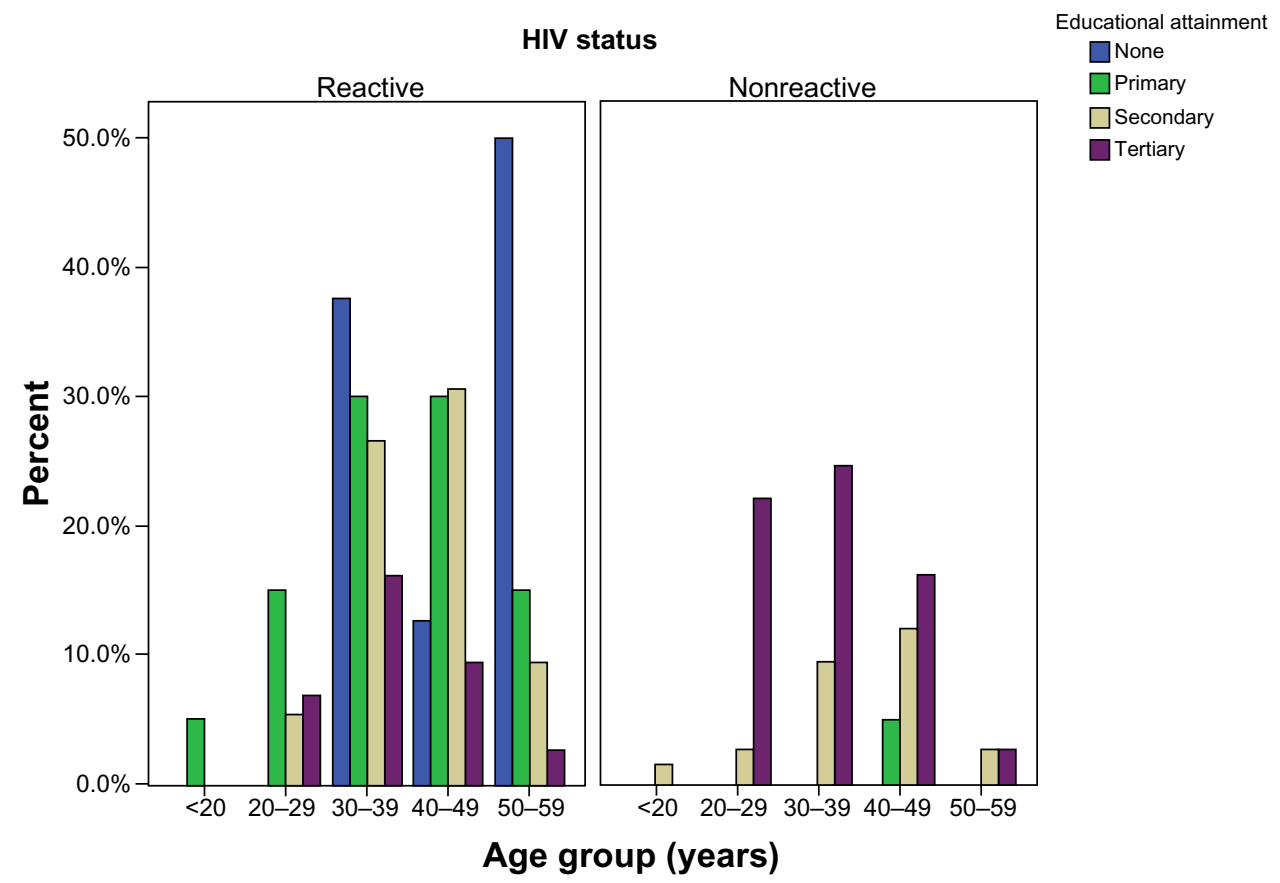

Figure I Distribution of education by age group according to HIV status. Abbreviation: HIV, human immunodeficiency virus. 


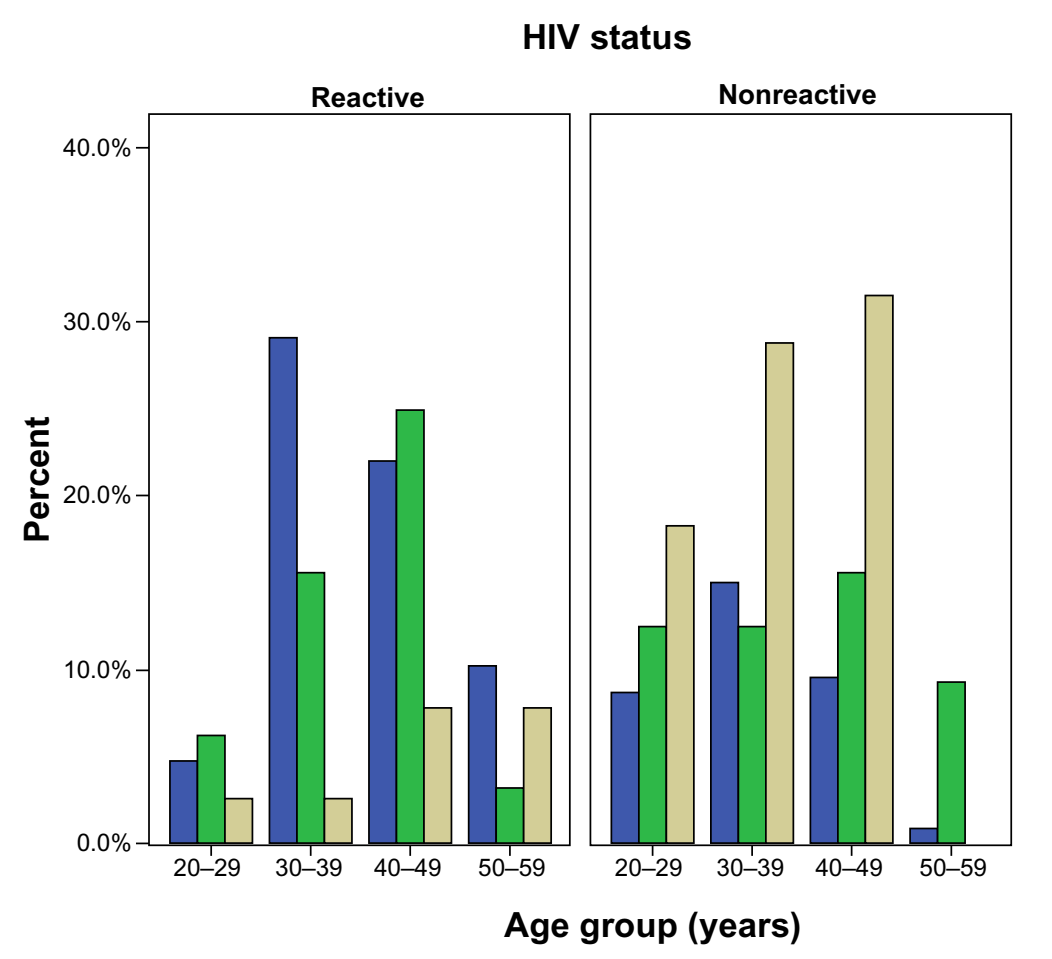

Figure 2 Distribution of income per month in Naira by age group according to HIV status. Abbreviation: HIV, human immunodeficiency virus.

implementing prevention programs. It has been reported that people with higher SES have a greater risk for HIV during the early stages of the epidemic, but that as the epidemic matures, people of lower SES become disproportionately affected. ${ }^{18,19}$

We investigated the relationship between commonly used indicators of SES and HIV infection, namely education attainment, employment status, and monthly income. ${ }^{6,18}$ In Nigeria, particularly in the southwest, education attainment is a key marker of socioeconomic position. In our study, the relationship between various levels of educational attainment and HIV infection was statistically significant except for those without education. After a logistic regression model was applied, this relationship was maintained only with a secondary school level of educational attainment. This lack of association between HIV infection and primary and tertiary school levels of education may reflect the possibility that the most important mediating factors were not included in our model. Those included may also have some peculiar relationship with other factors.

The finding that there is a significant relationship between secondary school attainment and risk for HIV infection may reflect poor parental involvement in adolescence, because the socialization that accompanies puberty and adolescent life adventures evolves during the secondary school stage.
Limited parental involvement seems to be generally associated with higher levels of premarital sexual activity and problem behaviors. ${ }^{19}$ This may be translated into a higher risk of HIV infection, and therefore more people living with HIV/AIDS, in the future. Furthermore, these same people are likely to marry men or women of their own educational level, who are also likely to engage in risky sexual behavior and incur the possibility of HIV infection. It is common knowledge in rural Nigeria's social context that many secondary school dropouts are linked to premature or unplanned pregnancies in women and to negative social behaviors in men. Further study at the secondary school level and programs that address the predilection to HIV infection (with the involvement of parentteacher associations) may be worthwhile. Previous reports in Zambia and Tanzania showed that education bears an inverse relationship to the risk of HIV infection. ${ }^{20,21}$ The difference in our findings may be because of the different methodologies, particularly in relation to differences in the confounders considered. Several reports have shown a similarly mixed result, ${ }^{22}$ which suggests the complexity of the relationship to risk at the individual, household, and community levels.

Employment status in our investigation did not show any relationship to risk of HIV infection. This is not unexpected, because the majority of our subjects were female. Culturally, Nigerian women are psychologically attached to 
the employment status of their husband. This was not evaluated in this study but may serve as a future area of research. In addition, male-partner employment status was not explored. Consideration of this status may also yield different results, because many unemployed men may be married to women with highly lucrative jobs that may effectively cater to their family's needs.

Monthly income bears a statistically significant inverse relationship with HIV infection. The lower the monthly income, the higher the risks of HIV infection even after the effects of confounders have been considered. This finding may be related to the high vulnerability of lowincome earners to many social vices in our environment. In sub-Saharan Africa, poverty has been associated with the distribution of HIV infection and high-risk sexual behaviors. $^{23,24}$ As a result, one of the strategies used by some HIV prevention programs in sub-Saharan Africa has been to empower HIV patients, and particularly women, to become more economically independent through microfinance loan schemes. ${ }^{25}$

Low income may make an individual vulnerable to accepting a risky situation that will provide for his or her daily needs. This includes multiple sexual exposures for financial gain. People with low incomes are also prone to unstable housing. This has been linked to the risk for HIV infection. ${ }^{9}$

A number of factors might have contributed to the limitations of our study. These include other potential confounders and effect modifiers, such as the number of partners participants have or had, the partner's SES, the participant's history of sexually transmitted disease, and their ethnicity. We would maintain that sexually transmitted diseases and number of partners are on the causal pathway under investigation between HIV and SES and should not be adjusted for as confounders in any analysis. Our study center is located in the southwest of Nigeria, where the population is predominantly from the Yoruba ethnic group. Therefore, introducing ethnicity may bias our study because of skewed ethnic population groups that may not adequately capture differences across ethnic groups. This may result in a low power to detect interethnic variation in HIV prevalence.

In conclusion, our findings suggest that education, income, and employment status have different relationships to HIV infection. While employment status showed no relationship to HIV infection, having a secondary school level of education showed a significant relationship. Income earned suggested an inverse relationship in all categories. The prevalence of HIV infections is now concentrated among those with low incomes. Urgent measures to improve HIV prevention among low-income earners are necessary. Future studies should use multiple measures in relation to partners' SES (measured by education, employment, and income) to further define this relationship.

\section{Disclosure}

The authors report no conflicts of interest in this work.

\section{References}

1. Central Intelligence Agency. The World Factbook. Washington, DC, USA: Central Intelligence Agency; 2012. Available from: https://www. cia.gov/library/publications/the-world-factbook/index.html. Accessed December 3, 2013.

2. Perry MJ. Gender, race and economic perspectives on the social epidemiology of HIV infection: implications for prevention. J Prim Prev. 1998;19(2):97-104.

3. Michelo C, Sandøy IF, Fylkesnes K. Marked HIV prevalence declines in higher educated young people: evidence from population-based surveys (1995-2003) in Zambia. AIDS. 2006;20(7):1031-1038.

4. Shelton JD, Cassell MM, Adetunji J. Is poverty or wealth at the root of HIV? Lancet. 2005;366(9491):1057-1058.

5. Van Howe R. Review of Chin J, The AIDS Pandemic: The Collision of Epidemiology with Political Correctness [homepage on the Internet]. East Lansing, MI: H-Net Reviews; 2007. Available from: http://www.h-net.org/reviews/showrev.php?id=13865. Accessed December 3, 2013.

6. American Psychological Association Task Force on Socioeconomic Status. Report of the APA Task Force on Socioeconomic Status. Washington, DC, USA: American Psychological Association; 2006. Available from: http:/www.apa.org/pi/ses/resources/publications/ task-force-2006.pdf. Accessed December 3, 2013.

7. Adler NE. Appendix D. Overview of health disparities. In: Thompson GE Mitchell F, Williams MB, editors. Examining the Health Disparity Research Plan of the National Institutes of Health: Unfinished Business. Washington, DC, USA: National Academies Press; 2006:121-174.

8. Ickovics JR, Beren SE, Grigorenko EL, Morill AC, Druley JA, Rodin J. Pathways of risk: race, social class, stress, and coping as factors predicting heterosexual risk behaviors for HIV among women. AIDS Behav. 2002;6(4):339-350.

9. Aidala A, Cross JE, Stall R, Harre D, Sumartojo E. Housing status and HIV risk behaviors: implications for prevention and policy. AIDS Behav. 2005;9(3):251-265.

10. Lagarde E, Enel C, Seck K, et al; MECORA group. Etude Multisite des Comportements et MST en zone Rurale d'Afrique. [Religion and protective behaviours towards AIDS in rural Senegal.] AIDS. 2000;14(13):2027-2033.

11. Shisana O, Zungu-Dirwayi N, Toefy Y, Simbayi LC, Malik S, Zuma K. Marital status and risk of HIV infection in South Africa. S Afr Med J. 2004;94(7):537-543.

12. Agadjanian V. Gender, religious involvement, and HIV/AIDS prevention in Mozambique. Soc Sci Med. 2005;61(7):1529-1539.

13. Joint United Nations Programme on HIV/AIDS (UNAIDS). Global Report: UNAIDS Report on the Global AIDS Epidemic 2013. Geneva, Switzerland: UNAIDS; 2013. Available from: http://www.unaids. org/en/media/unaids/contentassets/documents/epidemiology/2013/ gr2013/UNAIDS_Global_Report_2013_en.pdf. Accessed December 7, 2013.

14. National Agency for the Control of AIDS (NACA). The Presidents' Comprehensive Response Plan for HIV/AIDS in Nigeria. Abuja, Nigeria: NACA; 2013. Available from: http://www.zero-hiv.org/wp-content/ uploads/2013/09/PCRP-2013-2015-real-2-Aug-2013.pdf. Accessed December 7, 2013. 
15. National Agency for the Control of AIDS (NACA). United Nations General Assembly Special Session (UNGASS) Country Progress Report: Nigeria. Reporting period: Jan 2008-Dec 2009. Abuja, Nigeria: NACA; 2010. Available from: http://data.unaids.org/Pub/report/2010/ nigeria_2010_country_progress_report_en.pdf. Accessed December 7, 2013.

16. Ogun SA, Adelowo OO, Familoni OB, Jaiyesimi AE, Fakoya EA. Pattern and outcome of medical admissions at the Ogun State University Teaching Hospital, Sagamu - a three year review. West Afr J Med. 2000;19(4):304-308.

17. National Bureau of Statistics, Ministry of Planning, Empowerment and Economics. Tanzania HIV/AIDS Indicator Survey 2003-2004. Dar es Salaam, Tanzania: National Bureau of Statistics; 2010. Available from: http://www.nbs.go.tz/tnada/index.php/catalog/6/download/23. Accessed December 03, 2013.

18. Rutstein SO, Johnson K. DHS Comparative Reports No 6: The DHS Wealth Index. Calverton, MD: ORC Macro; 2004. Available from: http:// www.measuredhs.com/pubs/pdf/CR6/CR6.pdf. Accessed December 7, 2013.

19. Bingham CR, Crockett LJ. Longitudinal adjustment patterns of boys and girls experiencing early, middle, and late sexual intercourse. Dev Psychol. 1996;32(4):647-658.
20. Hargreaves JR, Howe LD. Changes in HIV prevalence among differently educated groups in Tanzania between 2003 and 2007. AIDS. 2010;24(5):755-761.

21. Msisha WM, Kapiga SH, Earls F, Subramanian SV. Socioeconomic status and HIV seroprevalence in Tanzania: a counterintuitive relationship. Int J Epidemiol. 2008;37(6):1297-1303.

22. Wojcicki JM. Socioeconomic status as a risk factor for HIV infection in women in East, Central and Southern Africa: a systematic review. J Biosoc Sci. 2005;37(1):1-36.

23. Cohen D. Issues Paper No 27: Poverty and HIV/AIDS in Sub-Saharan Africa. New York, NY: United Nations Development Programme; 1998. Available from: http://www.undp.org/content/dam/aplaws/publication/ en/publications/hiv-aids/poverty-and-hiv-aids-in-sub-saharan-africa/87. pdf. Accessed December 7, 2013.

24. Piot P, Bartsos M, Ghys PD, Walker N, Schwartländer B. The global impact of HIV/AIDS. Nature. 2001;(410):968-973.

25. Sugiyama M. Hoping and Coping: A Call for Action, the Capacity Challenge of HIV/AIDS in Least Developed Countries. United Nations Office Newsletter. Fall 2005:5. Available from: http://www.wfwp. org/wfwpi/library/news/WFWPIFall05.pdf. Accessed December 03, 2013.
HIV/AIDS - Research and Palliative Care

\section{Publish your work in this journal}

HIV/AIDS - Research and Palliative Care is an international, peerreviewed open-access journal focusing on advances in research in HIV, its clinical progression and management options including antivira treatment, palliative care and public healthcare policies to control viral spread. The journal welcomes original research, basic science,

\section{Dovepress}

clinical \& epidemiological studies, reviews \& evaluations, expert opinion \& commentary, case reports \& extended reports. The manuscript management system is completely online and includes a very quick and fair peer-review system. Visit http://www.dovepress.com/ testimonials.php to read real quotes from published authors. 